\title{
The Relationship between Disabled College Students' Psychological Capital and Employability
}

\author{
$\mathrm{Xu} \mathrm{Chao}{ }^{1,2}$ \\ ${ }^{1}$ School of Economics and Management \\ Hebei University of Technology, \\ ${ }^{2}$ Jingu College \\ Tianjin Radio and TV University \\ Tianjin, China
}

\author{
Yu Huixin \\ School of Economics and Management \\ Hebei University of Technology \\ Tianjin, China
}

\begin{abstract}
Psychological capital is an important factor affecting employability. Based on a survey of 451 disabled college students with the psychological capital questionnaire and employability questionnaire, this study aims to explore the relationship between disabled college students' psychological capital and employment performance.. The predictive effect of psychological capital on their employability was investigated and tested by correlation analysis and regression analysis. The result from this study indicates four aspects. (1)The disabled college students show a medium level of psychological capital and employability. (2) The degree of disability and age distribution affect the employability of disabled college students. (3) There is a significant positive correlation between psychological capital and employability of disabled college students. (4) Selfacceptance, optimism and resilience of psychological capital have predictive effects on disabled college students' employability.
\end{abstract}

Keywords-psychological capital; employability; disabled college students; self-acceptance

\section{INTRODUCTION}

In the report of the Nineteenth National Congress of the CPC, it was pointed out that we should comprehensively "promote education equity", "run special education well", vigorously "improve the quality of employment and income level", and "achieve higher quality and full employment". Improving the employment ability of disabled college students is not only related to their individual level of economic income, self-realization and social integration, but also related to whether disabled college students can effectively transform into human resources, thus promoting the sustainable development of society and the country. However, the employment situation of disabled college students is not optimistic. According to the data of the second national sample survey, the employment rate of disabled people with junior college education or above is only $58.1 \%$ [1]

For disabled college students, higher education means not only the improvement of knowledge and ability, but also the hope of integration into society. They hope to avoid physical defects and improve their employability by mastering a higher level of knowledge, so as to obtain employment opportunities and realize self-worth and social identity. However, there are many problems in disabled college students, such as weak

Fund Project: Tianjin Education Science 13th Five-Year Plan Project "Research on the Construction of Learning Support Service System for Disabled Students in Distance Education" (Project No.: CEYP5076); The Open University Youth Project "Research on the Impact Mechanism and Promotion of Employment Ability of Disabled Students in Distance Education - Based on the Perspective of Psychological Capital" (Project No.: G18A02123Q) employment ability, low level of employment and poor employment stability, which are far from their employment expectations. These problems have seriously impacted the employment confidence of disabled college students and deepened their negative psychology such as inferiority, anxiety and fear. These negative psychological factors further affect the employment ability and quality of disabled universities. Therefore, how to improve the mental state of disabled college students and take it as a breakthrough to improve their employability and quality of employment has become an urgent problem to be solved.

At present, some scholars have carried out relevant research on the relationship between college students' psychological capital and employability. Li Hua et al. [2] found that there are significant differences in the employability of college students in gender and grade, and there is a significant positive correlation between college students' psychological capital and their employability. Psychological capital has a good positive predictive effect on college students' employability. Wang Yaojun[3] found that the three dimensions of self-efficacy, resilience and optimism in psychological capital have a positive impact on college students' employability. By cultivating and improving psychological capital, college students' employability can be effectively improved. Liu Linlin et al.[4] found that psychological capital has a significant role in promoting the employability of college students through a survey of 768 College students. The higher the level of psychological capital of college students, the stronger its role in promoting employability. Based on the correlation between college students' psychological capital and employability, scholars have also carried out research on the cultivation and intervention of college students' employability based on psychological capital. After investigating the current situation of college students' psychological capital, Shen Xiaomei[5] pointed out that college students' psychological capital should be developed from four aspects: self-efficacy, optimism, hope and resilience. Gao Yan et al.[6] found that the improvement of psychological capital can effectively promote the employability of college students through the group counseling and training of psychological capital with the main content of "symbolization, self-reflection and inclusion of the present". In addition, some scholars have extended the 
relationship between psychological capital and employability to disabled college students. $\mathrm{Yu} \mathrm{Lu[7]}$ analyzed the relationship between career values, self-efficacy and employability of disabled people through quantitative research methods such as questionnaires, and pointed out that career values have a significant positive impact on the employability of disabled distance learners. However, the related research mainly concentrates on the qualitative analysis level, and the quantitative research is relatively few, especially from the perspective of psychological capital to quantitatively analyze the impact mechanism of employability and the promotion strategy.

Based on this, the research takes the theory of positive psychology as the foundation and the disabled students as the research object, explores the mechanism of the influence of psychological capital on the employment ability of disabled students, and clarifies the influencing factors of the employment ability of disabled students from the perspective of psychological capital, so as to provide specific theoretical basis for higher education institutions to enhance the employability of disabled students.

\section{RESEARCH DESIGN}

\section{A. Objects of study}

The data were collected from 637 students of the Disabled Education College in Open University. A total of 637 questionnaires were collected, of which 451 were valid, with an effective rate of $70.8 \%$. The basic information of the subjects is shown in Table I.

TABLE I. THE BASIC SITUATION OF THE OBJECT

\begin{tabular}{|c|c|c|c|c|c|c|c|}
\hline Sex & No. & Types & No. & Degrees & No. & Age & No. \\
\hline Man & 215 & Physical & 312 & Grade I & 54 & Under 20 & 9 \\
\hline Women & 236 & Hearing & 83 & Grade II & 85 & $20-29$ & 123 \\
\hline & & Visual & 39 & Grade III & 162 & $30-39$ & 200 \\
\hline & & Language & 17 & Grade IV & 150 & $40-49$ & 106 \\
\hline & & & & & & 50 and over & 13 \\
\hline
\end{tabular}

Among these responses, $47.7 \%$ were male and $52.3 \%$ were female. In terms of types of disability, $69.2 \%$ of the respondents were physical disability; $18.4 \%$ of the respondents were hearing disability, $8.6 \%$ of the respondents were visual disability and $3.8 \%$ of the respondents were language disability. In terms of degrees of disability, $12.0 \%$ of the respondents were grade- I disabled,18.8\% of the respondents were grade- $\Pi$ disabled,35.9\% of the respondents were grade-disabled,33.3\% of the respondents were grade-IV disabled. In terms of ages, $2 \%$ of the respondents were under $20 ; 27.3 \%$ of the respondents were between 20 and $29 ; 44.3 \%$ of the respondents were between 30 and $39,23.5 \%$ of the respondents were between 40 and $49,2.9 \%$ of the respondents were 50 or over.

\section{B. Tools of study}

1) Psychological capital scale of disabled college students

The self-designed mental capital scale for disabled college students was adopted. Firstly, we conduct in-depth interviews with individuals and groups to collect data, and use grounded theory research methods to extract the theoretical structure of psychological capital of disabled college students through three-level coding (open coding-spindle coding-selective coding); secondly, on this basis, we compile the initial scale of psychological capital of disabled college students. After testing and revising, the mental capital measurement scale for disabled college students was finally formed, with 16 items, including four factors: self-acceptance, hope, optimism and resilience.

\section{2) Employability scale of disabled college students}

This paper adopts the Employment Ability Measurement Scale for Disabled College Students compiled by the author in previous studies. The original scale has four dimensions, including 22 items ( 7 questions of professional identity, 5 questions of self-efficacy, 6 questions of interpersonal communication and 4 questions of human capital). Likert 5point scale was used to evaluate the scale. The higher the score, the higher the employability. In order to make the scale more practical in the study, the study used Sy (2010) as a reference to simplify the Employment Capability Measurement Scale. Each dimension only retains the three items with the highest factor load on that dimension for measurement. Therefore, through exploratory factor analysis and project selection, this study obtained a short version of the formal questionnaire with 4 dimensions and 12 items.

\section{3) Data Processing}

The SPSS21.0 was used for exploratory factor analysis, correlation analysis and regression analysis, and Amos22.0 was used for confirmatory factor analysis.

\section{RESULTS}

\section{A. Common method deviation test}

The measurements in this study all come from the same sample. In order to avoid serious deviation of common methods, this study randomly arranges the items of measurement and fills them out anonymously. At the same time, after the measurement data are retrieved, Harman single factor test was used to test the deviation of common method. It was found that there was 6 factor whose eigenvalue was greater than 1, and the variance of maximum factor interpretation was $21.85 \%$, which was lower than the critical value of $40 \%$. It indicates that there was no common method deviation.

\section{B. Eliability and validity of the scale}

According to the criteria of psycho metrology, the research tool should go through scientific test, then the test results are reliable and credible[8]. This scientific test includes reliability analysis and validity analysis.

\section{1) Reliability analysis of scale}

Reliability of a measure refers to its stability and internal consistency. Internal consistency can be estimated by Cronbach's $\alpha$ coefficient. Reliability of Psychological Capital Scale for Disabled College Students: Cronbach's $\alpha$ coefficient of overall questionnaire is 0.886 , and Cronbach's $\alpha$ coefficient of each subscale ranges from 0.729 to 0.834 , all the coefficients are greater than 0.7. Reliability of EmployabilityScale for Disabled College Students: Cronbach's $\alpha$ coefficient of overall questionnaire is 0.860 , and Cronbach's $\alpha$ coefficient of each subscale ranges from 0.672 to 0.826 , all 
the coefficients are greater than 0.60. Detailed data are shown in Table II.These suggests that Psychological Capital Scale and Employability Scale for Disabled College Students have good internal consistency and stability. Therefore, results of statistical analysis based on the questionnaire data are reliable.

TABLE II. RELIABILITY OF PSYCHOLOGICAL CAPITAL SCALE AND EMPLOYABILITY SCALE

\begin{tabular}{|c|c|c|c|c|c|}
\hline $\begin{array}{c}\text { Psychological } \\
\text { Capital Scale }\end{array}$ & $\begin{array}{c}\text { self- } \\
\text { acceptance }\end{array}$ & hope & optimism & resilience & Total \\
\hline Cronbach's $\alpha$ & 0.834 & 0.824 & 0.729 & 0.820 & 0.886 \\
\hline $\begin{array}{c}\text { Employability } \\
\text { Scale }\end{array}$ & $\begin{array}{c}\text { career } \\
\text { identity }\end{array}$ & $\begin{array}{c}\text { self- } \\
\text { efficacy }\end{array}$ & $\begin{array}{c}\text { interpersonal } \\
\text { communication }\end{array}$ & $\begin{array}{c}\text { human } \\
\text { capital }\end{array}$ & Total \\
\hline Cronbach's $\alpha$ & 0.672 & 0.826 & 0.729 & 0.699 & 0.860 \\
\hline
\end{tabular}

2) Validity analysis of scale

Validity refers to the extent to which questionnaire succeeds in providing an accurate representation of measured object. It can be verified by considering construct validity and content validity. We employed factor analysis to test construct validity of questionnaire. Disabled college students' psychological capital is composed of four factors, and accounts for $63.753 \%$ of the variance. Amos 22.0 was used to conduct confirmatory factor analysis of the scale. The results were $\chi^{2} / \mathrm{df}=2.372, \mathrm{RMSEA}=0.046, \mathrm{RMR}=0.052, \mathrm{GFI}=0.958$, $\mathrm{NFI}=0.945, \mathrm{IFI}=0.967, \mathrm{CFI}=0.967$. The fitting indexes of the scale were good. Disabled college students' employability is composed of four factors, and accounts for $66.230 \%$ of the variance. Amos 22.0 was used to conduct confirmatory factor analysis of the scale. The results were $\chi^{2} / \mathrm{df}=2.107$, RMSEA $=0.041, \quad$ RMR $=0.046, \quad$ GFI $=0.975, \quad \mathrm{NFI}=0.961$, $\mathrm{IFI}=0.979, \mathrm{CFI}=0.979$. The fitting indexes of the scale were good. Detailed data are shown in Table III .Therefore, Psychological Capital Scale and Employability Scale for Disabled College Students have good construct validity and discriminatory validity.

TABLE III. THE FITTING INDEXES OF PSYCHOLOGICAL CAPITAL SCALE AND EMPLOYABILITY SCALE

\begin{tabular}{|c|c|c|c|c|c|c|c|}
\hline & $\chi^{2} / \mathrm{df}$ & RMSEA & RMR & GFI & NFI & IFI & CFI \\
\hline $\begin{array}{c}\text { Psychological } \\
\text { Capital Scale }\end{array}$ & 2.372 & 0.046 & 0.052 & 0.958 & 0.945 & 0.967 & 0.967 \\
\hline $\begin{array}{c}\text { Employability } \\
\text { Scale }\end{array}$ & 2.107 & 0.041 & 0.046 & 0.975 & 0.961 & 0.979 & 0.979 \\
\hline
\end{tabular}

\section{Descriptive statistical analysis of psychological capital} and employability for disabled college students

The mean and standard deviation of psychological capital and employability of disabled college students were analyzed by descriptive statistics. The results are shown in Table IV.

TABLE IV. DESCRIPTIVE STATISTICAL RESUlts OF PSYCHOLOGICAL CAPITAL AND EMPLOYABILITY

\begin{tabular}{|c|c|c|c|c|c|}
\hline & $\mathrm{N}$ & Minimum & Maximum & Mean & Std. Deviation \\
\hline self-acceptance & 451 & 1.00 & 5.00 & 3.031 & 1.066 \\
\hline hope & 451 & 1.00 & 5.00 & 3.414 & 0.994 \\
\hline optimism & 451 & 1.00 & 5.00 & 2.979 & 0.887 \\
\hline resilience & 451 & 1.00 & 5.00 & 2.984 & 1.011 \\
\hline Psy. capital & 451 & 1.00 & 5.00 & 3.102 & 0.756 \\
\hline employability & 451 & 1.00 & 5.00 & 2.794 & 0.779 \\
\hline
\end{tabular}

The average value of psychological capital of disabled college students is 3.102, which is in the middle level. The scoring range of each dimension ranged from 2.979 to 3.414 , with "hope" scoring the highest $(\mathrm{M}=3.414)$ and "optimism" scoring the lowest $(\mathrm{M}=2.979)$. The average employment ability of disabled college students is 2.794 , which is in the lower middle level.

D. Correlation analysis between four factors of disabled college students' psychological capital and employability

The correlation analysis was made between the average score of each factor of disabled college students' psychological capital and the average score of disabled college students' employability.

The results of correlation analysis are shown in Table V It can be seen from Table $\mathrm{V}$ that, the correlation coefficients between self-acceptance, hope, optimism, resilience of psychological capital and employability of disabled college students are between 0.349 and 0.591.The correlation coefficient are all higher than the non-owning subscale, which indicates that, self-acceptance, hope, optimism, and resilience are significantly positive correlated with employability.

TABLE V. RELATIONSHIP BETWEEN FOUR FACTORS OF PSYCHOLOGICAL CAPITAL AND EMPLOYABILITY

\begin{tabular}{|c|c|c|c|c|c|}
\hline & $\begin{array}{c}\text { self- } \\
\text { acceptance }\end{array}$ & hope & optimism & resilience & employability \\
\hline $\begin{array}{c}\text { self- } \\
\text { acceptance }\end{array}$ & 1.000 & $0.436^{* *}$ & $0.360^{* *}$ & $0.617^{* *}$ & $0.591^{* *}$ \\
\hline hope & $0.436^{* *}$ & 1.000 & $0.296^{* *}$ & $0.509^{* *}$ & $0.349^{* *}$ \\
\hline optimism & $0.360^{* *}$ & $0.296^{* *}$ & 1.000 & $0.416^{* *}$ & $0.455^{* *}$ \\
\hline resilience & $0.617^{* *}$ & $0.509^{* *}$ & $0.416^{* *}$ & 1.000 & $0.573^{* *}$ \\
\hline Psy. capital & $0.807^{* *}$ & $0.739^{* *}$ & $0.656^{* *}$ & $0.840^{* *}$ & $0.648^{* *}$ \\
\hline
\end{tabular}

\section{E. Regression analysis on four factors of disabled college} students' psychological capital and employability

The results of correlation analysis show that there are positive correlations between the four factors of disabled college students' psychological capital and their employability. In order to further explore the impact of four factors on predictions of employability, a stratified regression was used to test the predictive effect of four dimensions of psychological capital on employability of disabled college students.

The first step is to make regression analysis by taking gender, disability degree and age as independent variables and employability of disabled college students as dependent variables. Model 1 in Table VI shows that types of disability and degrees of disability have a significant positive impact on employability of disabled college students.

The second step is to test the predictive effect of various dimensions of psychological capital on employability of disabled college students by taking gender, disability degree and age as control variables. Model 2 in Table VI shows that three dimensions of psychological capital of disabled college students enter the regression equation of employability, which are self-acceptance, optimism and resilience. They can explain $46.2 \%$ variation of "employability". The regression equation is employability $=0.347 \times$ self-acceptance $+0.212 \times$ optimism + $0.267 \times$ resilience. Therefore, three factors of psychological 
capital of disabled college students, which include selfacceptance, optimism, and resilience, are significant predictors of employability. The rankings of predictive power of three dimensions from high to low are: self-acceptance, resilience, and optimism. In order to further promote employability, managers should do their best on these factors.

TABLE VI. THE REGRESSION ANALYSIS ON FOUR FACTORS OF PSYCHOLOGICAL CAPITAL AND EMPLOYABILITY

\begin{tabular}{|c|c|c|}
\hline \multirow{2}{*}{ Variable } & \multicolumn{2}{|c|}{ Employability } \\
\cline { 2 - 3 } & Model1 & Model2 \\
\hline Control variable & & 0.038 \\
\hline Sex & 0.051 & 0.051 \\
\hline Degree & $0.148 * * *$ & 0.020 \\
\hline Age & $0.107 * *$ & $0.347 * * *$ \\
\hline Independent variable & & -0.012 \\
\hline Self-acceptance & & $0.212^{* * *}$ \\
\hline Hope & & $0.267 * * *$ \\
\hline Optimism & & 0.462 \\
\hline Resilience & 0.038 & 0.456 \\
\hline R2 & 0.033 & 0.424 \\
\hline Adjusted R2 & 0.038 & $80.047 * * *$ \\
\hline$\Delta$ R2 & $8.608 * * *$ & $\mathrm{~N}=451, * \mathrm{p}<0.05, * * \mathrm{p}<0.01, * * * \mathrm{p}<0.001$ \\
\hline $\mathrm{F}$ & &
\end{tabular}

\section{SUGGESTIONS AND CONCLUSIONS}

This paper explores the relationship between psychological capital and employability of disabled college students. On the basis of relevant research conclusions and combined with the group characteristics of disabled college students, this paper puts forward that,improve the level of psychological capital of disabled college students, and effectively enhance the employment ability of disabled college students. Colleges and universities should carry out psychological counseling courses and activities with self-acceptance as the main content, and create a positive psychological state by cultivating disabled college students' objective self-awareness and evaluation, so as to improve the level of psychological capital, enhance employment confidence and employment ability.

This study draws the following conclusions: (1) The degree and age distribution of disability affect the employability of disabled college students. (2) There is a significant positive correlation between psychological capital and employability of disabled college students. (3) Selfacceptance, optimism and resilience of psychological capital have predictive effects on employment ability.

\section{REFERENCES}

[1] Office of the second national sample survey of disability. Data from the second national sample survey of disability . Bei Jing: China Statistics Press,2007. (In Chinese)

[2] Li Hua, Cao Xingtian. Research on the relationship between college students' psychological capital and employability [J]. China Higher Education Research, 2011(3):54-56. (In Chinese)

[3] Wang Yaojun. The impact of psychological capital on college students employability [J]. Applied Psychology, 2013, 19(1):65-71. (In Chinese)

[4] Liu Linlin, Ye Baojuan, Fang Xiaoting, etc.. The relationship between psychological capital and employability of college students: mediating and regulating role of peer support $[\mathrm{J}]$. Chinese Journal of Clinical Psychology, 2017, 25(3):536-538. (In Chinese)

[5] Shen Xiaomei. Cultivation of college students' employability based on psychological capital $[\mathrm{J}]$. China Higher Education Research, 2013(12):90-93. (In Chinese)

[6] Gao Yan, Qiao Zhihong, Wu Xiaowei. Empirical research on employability improvement of college students based on vocational identity and psychological capital [J]. Exploration of Higher Education, 2017(3):107-112. (In Chinese)

[7] $\mathrm{Yu}$ Lu. A Study on the relationship between vocational values, selfefficacy and employability of disabled distance learners [D]. Tianjin University of Technology, 2016. (In Chinese)

[8] LING Wen-quan, ZHANG Zhi-can, FANG Li-luo. The research on the structure model of Chinese employee's organizational commitment[J]. Journal of Management Sciences in China, 2000, 3(2): 76-80. (In Chinese) 